\title{
Authentic computer science undergraduate research experience through computational science and research ownership
}

\author{
Lior Shamir \\ Lawrence Technological University \\ 21000 W Ten Mile Rd. \\ Southfield, MI, USA \\ Ishamir@mtu.edu
}

\begin{abstract}
Research experience has been identified as a high-impact intervention for increasing student engagement and retention in STEM. However, authentic undergraduate research leading to primary authorship peer-reviewed publications is a challenge due to the relatively short time the students work on their capstone projects, and the insufficient preparation of the students as researchers. The challenge is further magnified in the field of computer science, where the absence of "traditional" labs limits the opportunities of undergraduate students to participate in research. Here we present a novel approach to authentic computer science undergraduate research, based on interdisciplinary computational science and student ownership of their research projects. Instead of the traditional role of undergraduate research assistant, the students select their own research topic based on their personal interests, and with the assistance of a faculty complete all stages of their research project. The uniqueness of the approach is its ability to lead to scientific discoveries and peer-reviewed publications such that the primary author is the student, while allowing the student to experience the entire research process, from defining the research question through analysis of the experimental results. In three years the model led to a dramatic increase in the number of undergraduate students who publish primary-author peer-reviewed scientific papers. The intervention increased the number of peer-reviewed student-authored publications from none to a very high rate of about one third of the students, in many cases publishing in the top outlets in their field.
\end{abstract}

\section{Categories and Subject Descriptors}

K.3.2 [Computers and education]: Computer and Information Science Education

\section{General Terms}

Experimentation, Human Factors

\section{INTRODUCTION}

Research experience has been becoming increasingly important in undergraduate education, and a primary tool for attracting and retaining students in the Science, Technology, Engineering, and Mathematics (STEM) disciplines [32, 29]. One of the goals of undergraduate research experience is to improve student learning [18], as it has been shown that active learning is superior to "traditional" teaching methodologies [12], also leading to higher grades [20,3]. Another goal is student preparation and ability to make connections among seemingly disparate pieces of information, evaluate evidence, and bring the requisite expertise to address complex issues [1].

In addition to enhancing the learning experience, researchbased education has been proven to be a powerful intervention for engaging undergraduate students [37], and consequently retaining students in STEM [16, 20, 25, 9, 29]. The possibility of making a discovery and the participation in authentic STEM research has substantial impact on student engagement and learning compared to classical experiment or "cookbook" style laboratory exercises that reproduce known results $[32,29]$.

In particular, research-based education was found effective for attracting underrepresented minority students to STEM $[3,48]$. Other proven interventions for underrepresented minorities in STEM include attending conferences, presenting at conferences, and faculty mentorship [48], which are also activities related to undergraduate research.

However, undergraduate research in computer science introduces several obstacles, making it more challenging than undergraduate research in many other STEM disciplines. Fields such as physics, chemistry, or biology offer a variety of hands-on opportunities for undergraduate research. Undergraduate students can join research labs and participate in experiments by executing protocols, preparing materials, or operating basic research equipment. Such research labs provide opportunities for undergraduate students to become familiar with the environment of a research lab. As a result, undergraduate students have noticeable presence in research labs in these disciplines, and are often authors on scientific peer-reviewed publications. Although the experiments are normally designed by more senior researchers, undergraduate students can take part in the research and benefit greatly from their presence at the lab and their work as part of a 
research team in a discovery-driven environment.

Research in computer science, on the other hand, normally requires deep knowledge of the concepts being studied and familiarity with the state-of-the-art literature [30], making it more difficult for an undergraduate student to make a contribution.

Therefore, undergraduate research experience in computer science can be broadly divided into two primary categories: The first is student independent capstone projects, driven by student ideas and the personal interest of the student. Students working on these projects often receive the assistance of a faculty or industry supervisor, but the project is normally owned by the student, who leads it through all stages of the development [28]. The downside of these capstone projects is that they rarely lead to peer-reviewed scientific publications and authentic scientific discoveries.

The second category is student research assistantship [49, 5], in which the student joins a research project led by a faculty or another senior person, and assists them with the research. As a research assistant, the student is exposed to authentic research, but does not lead or own the research [19]. Another disadvantage of student research assistantship is that it is limited by available funding [31] and faculty attention [34], and therefore while some undergraduate students in computer science have the opportunity to join faculty or research labs, the majority of undergraduate students completing a four-year degree in computer science do not participate in authentic research or become authors on a peer-reviewed scientific paper. In some cases research opportunities are available for the most qualified and motivated students, and allowing all students to work on research requires a compromise on the research quality and expectations [4]. It should also be noted that undergraduate research experience in the form of research assistantship is far more common in research universities compared to other institution of higher education [44, 33], and therefore students in smaller universities have less opportunities experience research.

Here we describe a model of undergraduate research experience that combines student ownership with authentic research that leads to peer-reviewed publications such that the primary author is the student. The project is owned by the student and driven by the student's area of interest, while leading to authentic scientific discoveries and peer-reviewed publications. The model provides research opportunities to all undergraduate students, and significantly improved student engagement. It also dramatically increased the number of students publishing peer-reviewed papers from none to one third of the total number of graduating students.

\section{STUDENT RESEARCH ASSISTANT COM- PARED TO STUDENT RESEARCHER}

The typical way by which an undergraduate student is exposed to authentic STEM research is through the role of student research assistant. As a research assistant, the student joins a faculty or lab, and performs tasks related to the research under the direction of the primary investigator or another senior member in the lab. Although there is clearly high educational value in being part of a research team, the research assistantship model is imperfect for providing re- search experience to large numbers of students as part of their curricula.

Firstly, due to the close supervision that mentoring an undergraduate student in computer science requires, the primary investigators are limited by the number of undergraduate students they can mentor in their lab, and therefore just few of the undergraduate students have the opportunity to participate in research. Less senior members such as $\mathrm{PhD}$ candidates also have commitments that limit their ability to mentor students, and being trainees themselves they lack the training and experience to effectively mentor students and lead them to scientific discoveries. Undergraduate students working in labs often receive stipend for their work, making the number of students also limited by the availability of funding. Because of the limited number of available research assistantship positions, these positions are sometimes competitive, and students are selected based on their academic achievements, making the research experience inaccessible to those who are not at the top of their class.

Another downside of the student research assistant model is that the students are required to join an existing research project designed and led by a faculty, and therefore do not select their research topic by themselves. That limitation is magnified in smaller institutions of higher education, where the number of research programs is limited and the student has even less research options to choose from. Working on a research program led by a faculty also diminishes the aspect of ownership of the research, which is an important element of the undergraduate research experience [29, 2]. Another disadvantage of the student research assistantship model is that the student often performs specific tasks defined by the primary investigator or other supervisors, and therefore does not earn hands-on experience in performing the entire research process, from the definition of the research problem to the analysis of the experimental results.

According to the undergraduate research experience model proposed in this paper, the undergraduate research is performed such that the student serves as the researcher, and the faculty assists the student and provides the required knowledge to successfully complete the project. The student selects the research topic of his or her interest, defines the scientific question, designs the research, performs the experiments, and then analyzes the experiential results, while the faculty mentor assists the student and provides the knowledge required for the completion of each step of the research. That experience exposes the student to all stages of the research, and embraces the idea of student ownership rather than assisting the research agenda of a more senior person. The ability of the student to work on a research topic of their choice helps to engage the student in the research, and also attracts students who would not otherwise work on a research project. It can also lead to peer-reviewed scientific papers on which the undergraduate student is the primary author.

Table 1 shows a summary of the differences between the role of a student research assistant and the proposed model of student researcher. 
Table 1: Student research assistant vs. student researcher

\begin{tabular}{|l|c|c|}
\hline & Student research assistant & Student researcher \\
\hline Accessibility & Some (best) students & All students \\
\hline Owner of the research & Faculty & Student \\
\hline Selection of research topic & Faculty & Student \\
\hline Student responsibilities & Defined tasks & Entire research project \\
\hline Paper authorship & For some, as co-authors & Yes (if paper is published) \\
\hline Role of faculty mentor & Direct the student & Assist the student \\
\hline
\end{tabular}

\section{IMPLEMENTATION OF THE STUDENT RESEARCHER MODEL}

In the proposed program, the student projects normally span over two semesters, during which they earn three credit hours in each semester. The two project courses are mandatory for all students, although students are not required to perform research, and are free to choose to work with an industry partner, develop a video game, or work on their own technological invention that is not necessarily considered research. As will be described later in this paper, the number of students choosing to work on research increased dramatically since the described undergraduate research experience model was implemented.

The students do not work on existing research programs, and therefore the number of students that can perform research is not limited by the number of research labs or open research assistantship positions. However, supervising and mentoring students is still a time-consuming task for the faculty. As will be described in Section 4, the experience of implementing the program showed that one faculty can mentor the research programs of about 10 students. Since the ratio between faculty and senior students is normally lower than $1: 10$, the implementation of the program is feasible even in smaller institutions of higher education, or colleges where substantial part of the teaching is performed by part-time faculty members.

One of the key features of the scheme is that the students can choose their own research topics, based on their interest. In the beginning of the semester the student meets with the faculty mentor to discuss the topics the student is interested in, and the student and faculty collaboratively design a research plan that is as close as possible to these fields of interest. That is done in the first two weeks of the project. Examples of research projects will be described in Section 4.

One of the important aspects of the research topics is computational science and interdisciplinarity [7]. Most Undergraduate students do not have deep knowledge in the different sub-fields of computer science, and therefore the requirement to expand the state-of-the-art in a core computer science sub-discipline might not be in agreement with the preparation of the student and their ability to perform that type of research. In other cases research in these sub-disciplines of computer science might not be aligned with the interests of the student. Fortunately, computer science has application to many other fields, and the increasing availability of scientific data in these disciplines allows effective research and substantial scientific discoveries through computational science. Biology has long been a field with strong ties to computer science in the form of bioinformatics and com- putational biology, but other fields such as astronomy and geoscience are also in the process of establishing strong links to computer science, leading to interdisciplinary sub-fields. Since many of the students who choose computer science are also interested in astronomy, computational astronomy is a field of study that can attract undergraduate students to research. Other fields that are of high student interest can be zoology, art, music, literature, and sport. Allowing the students to choose a topic of research in these disciplines can engage the student in research, and more importantly, can attract students who would not otherwise participate in authentic scientific research. Students can also choose research topics related to their culture or ethnicity, and express their identity through computing.

The availability of scientific data that the students can process is often a critical requirement for completing the research, and therefore the student and faculty mentor should verify that the data are publicly available or can be obtained within a reasonable period of time. That ensures that the beginning of the project is not delayed because the data are not available. The analysis of the data can be done by modifying existing open source data analysis tools and adjusting them to the specific needs of the data analysis project.

When the students are provided with the option to select the research topics regardless of the existing research programs available on their campus, it is expected that some students would choose to study topics that the faculty mentor is not familiar with. To satisfy the expectations of the student, the faculty mentor can learn the new field with the student, leading to the expansion of the research topics that the faculty can mentor. Therefore, it can be expected that the implementation of the program will lead to a gradual increase in the variety of research programs the students can choose from.

The downside of the student self-selection of the research projects is that students are geared towards their own interests so that each student tends to pick the project by the topic, and not necessarily by the other students that they want to work with. The priority of the research topic over the research team results in much less teams of students, and some students who work on research tend to work by themselves. In fact, just about $25 \%$ of the students who chose to work on research worked in teams. That can be very different from non-research projects such as video games, where the vast majority of the students worked in teams. In that case, the students first select the team they want to work with, and only then they discuss the specific video game they wish to develop. 
Two semesters is a short time for completing a research project and submitting a scientific paper. Unlike graduate students who spend most of their time working on their thesis, undergraduates spend substantial part of their time taking courses, and sometimes have other commitments such as work, and therefore their progress is limited by the time they can commit to their research. For that reason it is important to meet the student at least once a week, as well as maintaining a channel of communication by email or other technologies (e.g., Skype) so that the student gets the support as soon as they need it, without delaying their progress. It is also the responsibility of the faculty to monitor the progress of the students and make sure the students use their resources efficiently, and make the correct implementation decisions during the semester. The level of student-faculty interaction therefore goes beyond the regular office hours. From the faculty perspective it means spending longer hours on campus meeting with students, and becoming available to the students at almost any time.

The open communication with the faculty mentor is also important for supporting the student. Undergraduate students who have no experience in research are naturally concerned about not being able to complete their project, and consequently failing the course. The communication with the faculty and the availability of the faculty assures the students that they receive the support they need to complete the project, and that the faculty is aware of their efforts and the solutions they develop as they attempt to solve the scientific question at hand. Working as a team with their faculty mentor can drastically reduce the anxiety, and make the research project a positive experience. For the same reason it is important to make a clear statement that the project is not graded by the ability of the student to provide a solution to the scientific problem by the end of the semester, but by the way the student studies the topic and approaches the scientific question in attempt to solve it. Such statement reduces the natural anxiety of the students who are asked to perform tasks they never attempted before, and might be worried about the academic consequences in case the problem they chose to work on does not cooperate with their solutions. Another reason is to encourage the student to choose more challenging research projects, and not necessarily the simpler problems that they know they can solve and secure a passing grade.

\section{RESULTS}

The program described above was implemented in our department, which has $\sim 120$ undergraduate students, and about 25-30 senior students. Before the implementation of the program the undergraduate students were rarely involved in research. In three years the program increased the number of students working on research from practically none to about $40 \%$ of the students. Students in the video game concentration have to develop a video game as part of their degree requirements, and cannot choose to work on a research project (for academic credits), so when excluding these students about half of the undergraduate students chose to work on a research project, while the others preferred to develop creative computer applications or work on industryoriented projects. Table 2 shows the distribution of the type of projects selected by the students. As the table shows, the number of students who chose to work on research increased dramatically when the program was first implemented in 2011, allowing the students to work on their own research projects. The drop in the number of students in 2014 can be associated with the financial crisis that hit the Detroit area in 2009-2011, affecting the number of senior students about four years later.

Table 2: Student selection of capstone projects. The new approach to student capstone projects was started in 2011.

\begin{tabular}{|c|c|c|c|}
\hline Year & Video games & Research & Other \\
\hline 2010 & 14 & 1 & 38 \\
\hline 2011 & 16 & 22 & 25 \\
\hline 2012 & 12 & 24 & 21 \\
\hline 2013 & 11 & 21 & 19 \\
\hline 2014 & 7 & 12 & 15 \\
\hline 2015 & 6 & 18 & 14 \\
\hline 2016 & 8 & 21 & 16 \\
\hline
\end{tabular}

The increase in the number of students who participate in authentic research is also reflected by the number of students who become authors on peer-reviewed scientific papers. Before the implementation of the program none of the undergraduate students submitted papers to peer-reviewed journals or conferences. After the first year of the program two papers were published [47, 42], three papers in 2013 [36, $13,39]$, seven in 2014 [14, 43, 17, 11, 26, 46, 21], six in 2015 $[8,24,35,22,15,27]$, and seven in 2016 [23, 38, 41, 45, 40, $50,10]$.

The number of submitted papers peaked in the spring semester of 2013 , where out of 21 students eight papers were submitted with 11 student authors, more than half of the students in that semester. These papers were published during 2013 through 2015.

The student engagement is also reflected by the number of students who keep working on their project and meet regularly with the faculty after they graduate. A student who continues to work on their research makes an indirect statement about the level of engagement and commitment to their scholarly work. About one quarter of the students who work on research projects continue to come to campus and meet with their mentor faculty for at least one semester after they graduate.

One of the surprising observations of the experiment is the student response to publishing scientific papers. The experiment revealed a very positive attitude of undergraduate students toward publishing papers, and expressed willingness to put efforts in the preparation of papers also after they graduate. In some cases the students return to campus to work on revising their papers, as the report of the reviewers and editors is normally received after the student graduates. Another expression of student enthusiasm about publishing papers is explicit statements made by the student expressing their expectation to publish a paper, even before they chose their research topic. In addition to student pride and motivation, the communication of the student research results through peer-reviewed papers helps to defend the overall quality and impact of the student research, and helps to justify the engagement of students in research. 
An important aspect of the results observed in the first four years of the program is the impact of research experience on underrepresented minorities. Research experience has been demonstrated as one of the most powerful tools to attract and retain underrepresented minority groups in STEM [6, 48, 3], and the findings of this experiment are in strong agreement with these reports. Our department has a relatively small population of underrepresented minority students, but the effect was measured by the participation of women in research. Like many other computer science programs, our student population is dominated by male students. In 2013 the department had 114 male students and just 12 female students. However, the proportion of female students is completely different when considering the student-authored papers published so far. Out of 27 student-authored papers published so far, about $25 \%$ were authored by female students [47, 42, 26, 43, 24, 50, 10], much higher than the proportion of female student in the entire student population, which is $\sim 9 \%$. That proportion remains consistent also among the papers that are currently under review. It should be noted that the sample size is still too small to be statistically significant.

The presence of female students in research is also felt by news items in the mainstream media. Since 2011 we had four student research projects $[42,14,43,23]$ featured on the premier national and international popular press (e.g., NBC News, Fox News, CBS, NPR, Discovery Channel, Scientific American, The Atlantic, etc'), including press interviews with the students about their research. The exposure through the mainstream media elevated the research experience to a new level of pride and excitement for the students, their friends, and their families. Of these four students two were women. Although it is clear that the test group is far too small for making a conclusion, it is a result of female student engagement in the research, as the research topic is strongly related to the student's personal interests. Also, out of the 27 students that were authors on scientific papers, 10 continued to graduate school.

As mentioned in Section 3, the research project of each student starts with a meeting in which the student describes their interests to the faculty mentor, and then the topic of the research is defined by both the student and the faculty. Since different students have different topics of interest, supporting the interest of the students requires a broad range of research topics on which the students can perform their studies, and new topics and disciplines are added every year based on the student request. The first interdisciplinary program was bioinformatics and medical informatics [36, 26, 24, 41 , and based on the request of students was enhanced with astroinformatics $[17,11,21,35,22,23]$. Other programs that followed were Zoology [47, 43], art [42], music [14, 15, 13], literature [39], sports [46, 45, 50], and human aspects of computing $[8,38]$. All of these programs were added based on student interest and their expressed desire to perform research in these disciplines. One example is a student who was also a volunteer in a bird preservation society, and chose a project which applied computational science to study birds behavior and preservation [47]. A student who is an amateur artist chose to apply computational science to analyze art [42], a semi-professional rock musician used computational methods to analyze music [14], a football fan applied com- putational science to the analysis of football coach decisions [46], and a soccer fan chose to analyze the salaries of soccer players [50].

\subsection{Transferability of the model}

Working with every student and the need to learn new disciplines based on the student interest requires substantial efforts from the faculty. Therefore, the return should be weighted against the time investment to make the model transferable. Incentives for faculty to implement the model include publications and opportunities for external funding. Additionally, the opportunity to learn new disciplines can also have a certain value, and the engagement in research through education can be appealing to faculty at institutions that mostly focus on education.

This project was started without institutional funding, but led to several external grants directly or indirectly related to the work. For instance, an NSF grant (CNS-1157162) to fund a computing facility was based primarily on computational research performed by students. Another NSF grant (IIS-1546079) was received with substantial help from the work of students who were interested in computational astronomy. A grant from the AAC\&U was given partially for the work on computational analysis of art [42], and funded the implementation of this model in art history courses.

Peer-reviewed publications can also be an incentive for the faculty, as publications in competitive outlets often add to the reputation of their authors. However, the diverse nature of the papers and outlets does not necessarily lead to a solid career development path, and therefore career development in the sense of peer-reviewed publications is not a primary incentive.

\section{CONCLUSION}

Research experience is an effective intervention for attracting and retaining undergraduate students in STEM, and develop creativity and critical thinking skills [1]. Due to the deep knowledge required to perform research in computer science, as well as the limited open positions for student research assistants in labs, most computer science undergraduate students do not participate in authentic research before they graduate, or become authors on scientific papers.

Here we propose a model of interdisciplinary computer science undergraduate research that can provide research opportunities for undergraduate students. The model is based on student selection of their research topic and student ownership of the research, while the faculty assists the students to perform all stages of the research project, from the definition of the scientific question to the analysis of the experimental results. That model is different from the role of the student research assistant, in which the student joins an existing research program and follows the directions of the faculty supervisor. The primary advantages of the proposed model is its accessibility to all students, its ability to engage students by ownership of their research, and expose the students to hands-on experience in all stages of a research project.

The results show dramatic increase in the number of students participating in research, and consequently the num- 
ber of peer-reviewed papers authored by students. These results are achieved without the need for investment in more research labs or research assistantship positions, and without additional funding to support student stipends. However, the implementation of the program requires intensive interaction and frequent meetings with the student, and availability of the faculty far beyond the regular office hours.

An important requirement for successful implementation of the program is a broad range of interdisciplinary research topics that can engage and motivate students, and attract computer science students who would otherwise preferred to work on other projects that are not necessarily research. These research programs are different from the "establishment" research programs and topics normally expected from computer science faculty members. Therefore, the development of such programs also requires redefinition of the expected research achievements for the purpose of career decisions such promotion and tenure. While normally decisions regarding promotion or tenure are based on teaching and scholarship achievements, the model proposed here combines the two and makes it difficult to make a clear line that separates between them. Therefore, the "traditional" teaching-research-service scheme of faculty assessment for tenure and promotion might need to be adjusted to a model that has substantial overlap and strong link between teaching and research responsibilities, but also requires a different research agenda from the faculty who is interested in the implementation of such program.

\section{ACKNOWLEDGMENTS}

This work is supported in part by the TIDES program of the AAC\&U, with financial support from the Helmsley foundation. It was also supported by NSF grants IIS-1546079 and CNS-1157162.

\section{REFERENCES}

[1] American Association for the Advancement of Science. Vision and change - a call to action, 2009.

[2] L. C. Auchincloss, S. L. Laursen, J. L. Branchaw, K. Eagan, M. Graham, D. I. Hanauer, G. Lawrie, C. M. McLinn, N. Pelaez, S. Rowland, et al. Assessment of course-based undergraduate research experiences: a meeting report. CBE-Life Sciences Education, 13(1):29-40, 2014.

[3] A. E. Barlow and M. Villarejo. Making a difference for minorities: Evaluation of an educational enrichment program. Journal of Research in Science Teaching, 41(9):861-881, 2004.

[4] M. Beckerleg and J. Collins. Producing research from undergraduate projects. In Proceedings of the 18th Conference of the Australian Association for Engineering Education, pages 9-13, 2007.

[5] L. A. Beninson, J. Koski, E. Villa, R. Faram, and S. E. OâĂŹConnor. Evaluation of the research experiences for undergraduates (reu) sites program. CUR Quarterly, 32(1):43-48, 2011.

[6] J. A. Bianchini. Expanding underrepresented minority participation: America's science and technology talent at the crossroads. Science Education, 97(1):163-166, 2013.

[7] J. Blackmer. The gesture of thinking: Collaborative models for undergraduate research in the arts and humanities. plenary presentation at the 2008 cur national conference. CUR Quarterly, 29(2):8-12, 2008.

[8] B. Bock and L. Shamir. Assessing the efficacy of benchmarks for automatic speech accent recognition. In 8th International Conference on Mobile Multimedia Communications, 2015.

[9] J. M. Braxton, A. S. Hirschy, and S. A. McClendon. Understanding and Reducing College Student Departure: ASHE-ERIC Higher Education Report, volume 30. John Wiley \& Sons, 2011.

[10] A. Burcoff and L. Shamir. Computer analysis of pablo picassoâẮ́s artistic style. International Journal of Art, Culture and Design Technologies.

[11] L. Dojcsak and L. Shamir. Quantitative analysis of spirality in elliptical galaxies. New Astronomy, 28:1-8, 2014.

[12] S. Freeman, S. L. Eddy, M. McDonough, M. K. Smith, N. Okoroafor, H. Jordt, and M. P. Wenderoth. Active learning increases student performance in science, engineering, and mathematics. Proceedings of the National Academy of Sciences, page 201319030, 2014.

[13] J. George and L. Shamir. Computer-based approaches to music research. In Network Detroit: Theory and Practice, 2013.

[14] J. George and L. Shamir. Computer analysis of similarities between albums in popular music. Pattern Recognition Letters, 45:78-84, 2014.

[15] J. George and L. Shamir. Unsupervised analysis of similarities between musicians and musical genres using spectrograms. Artificial Intelligence Research, 4(2):61, 2015.

[16] W. v. Hippel, J. S. Lerner, S. R. Gregerman, B. A. Nagda, and J. Jonides. Undergraduate student-faculty research partnerships affect student retention. The Review of Higher Education, 22(1):55-72, 1998.

[17] C. Hoehn and L. Shamir. Characteristics of clockwise and counterclockwise spiral galaxies. Astronomische Nachrichten, 335(2):189-192, 2014.

[18] A.-B. Hunter, S. L. Laursen, and E. Seymour. Becoming a scientist: The role of undergraduate research in students' cognitive, personal, and professional development. Science Education, 91(1):36-74, 2007.

[19] M. Jonas. Capstone experience: lessons from an undergraduate research group in speech at unh manchester. In Proceedings of the 2011 conference on Information technology education, pages 275-280. ACM, 2011.

[20] D. H. Kinkel and S. E. Henke. Impact of undergraduate research on academic performance, educational planning, and career development. Journal of Natural Resources \& Life Sciences Education, 35(1):194-201, 2006.

[21] E. Kuminski, J. George, J. Wallin, and L. Shamir. Combining human and machine learning for morphological analysis of galaxy images. Publications of the Astronomical Society of the Pacific, 126(944):959-967, 2014.

[22] E. Kuminski and L. Shamir. Computer analysis of digital sky surveys using citizen science and manual 
classification. In American Astronomical Society Meeting, volume 225, 2015.

[23] E. Kuminski and L. Shamir. A computer-generated visual morphology catalog of $3,000,000$ sdss galaxies. The Astrophysical Journal Supplement Series, 223(2):20, 2016.

[24] E. Lixie, J. Edgeworth, and L. Shamir. Comprehensive analysis of large sets of age-related physiological indicators reveals rapid aging around the age of 55 years. Gerontology, 61(6):526-533, 2015.

[25] D. Lopatto. Undergraduate research experiences support science career decisions and active learning. CBE-Life Sciences Education, 6(4):297-306, 2007.

[26] S. Manning and L. Shamir. Chloe: A software tool for automatic novelty detection in microscopy image datasets. Journal of Open Research Software, 2(1):e25, 2014.

[27] I. Model and L. Shamir. Comparison of data set bias in object recognition benchmarks. IEEE Access, 3:1953-1962, 2015.

[28] B. Olsson, M. Berndtsson, B. Lundell, and J. Hansson. Running research-oriented final year projects for cs and is students. ACM SIGCSE Bulletin, 35(1):79-83, 2003.

[29] PCAST. Report to the president - engage to excel: Producing one million additional college graduates with degrees in science, technology, engineering, and mathematics, 2012.

[30] J. A. Polack-Wahl and K. Anewalt. Learning strategies and undergraduate research. In ACM SIGCSE Bulletin, volume 38, pages 209-213. ACM, 2006.

[31] M. Ramirez, J. McNicholas, B. Gilbert, J. Saez, and M. Siniawski. Creative funding strategies for undergraduate research at a primarily undergraduate liberal arts institution. CUR QUARTERLY, 36(2):5-8, 2015.

[32] S. H. Russell, M. P. Hancock, and J. McCullough. Benefits of undergraduate research experiences. Science, 316(5824):548-549, 2007.

[33] S. H. Russell, M. P. Hancock, J. McCullough, J. D. Roessner, and C. Storey. Evaluation of nsf support for undergraduate research opportunities: Survey of stem graduates. Evaluation, 2005.

[34] A. Schmolitzky and T. Schümmer. Patterns for supervising thesis projects. In EuroPLoP, 2008.

[35] A. Schutter and L. Shamir. Galaxy morphology-an unsupervised machine learning approach. Astronomy and Computing, 12:60-66, 2015.

[36] E. Schwartz and L. Shamir. Correlation between brain mri and continuous physiological and environmental traits using $2 \mathrm{~d}$ global descriptors and multi-order image transforms. Journal of Medical Imaging and Health Informatics, 3(1):12-16, 2013.

[37] E. Seymour, A.-B. Hunter, S. L. Laursen, and T. DeAntoni. Establishing the benefits of research experiences for undergraduates in the sciences: First findings from a three-year study. Science Education, 88(4):493-534, 2004.

[38] L. Shamir, D. Diamond, and J. Wallin. Leveraging pattern recognition consistency estimation for crowdsourcing data analysis. IEEE Transactions on
Human-Machine Systems, 126(944):959-967, 2015.

[39] L. Shamir and C. R. Everett, M. Computationally classifying literature with frequency analysis and pattern recognition. In Digital Humanities Theory and Practice. Network Detroit, 2013.

[40] L. Shamir and E. Kuminski. Image-based query-by-example for big databases of galaxy images. In American Astronomical Society Meeting Abstracts, volume 229, 2017.

[41] L. Shamir and J. Long. Quantitative machine learning analysis of brain mri morphology throughout aging. Current aging science, 4(9):1-7, 2016.

[42] L. Shamir and J. A. Tarakhovsky. Computer analysis of art. ACM Journal on Computing and Cultural Heritage, 5(2):7, 2012.

[43] L. Shamir, C. Yerby, R. Simpson, A. M. von Benda-Beckmann, P. Tyack, F. Samarra, P. Miller, and J. Wallin. Classification of large acoustic datasets using machine learning and crowdsourcing: Application to whale calls. The Journal of the Acoustical Society of America, 135(2):953-962, 2014.

[44] R. D. Slocum and J. D. Scholl. Nsf support of research at primarily undergraduate-institutions (puis). Council on Undergraduate Research Quarterly, 34(1):31-40, 2013.

[45] J. T. Soares and L. Shamir. Quantitative analysis of penalty kicks and yellow card referee decisions in soccer. American Journal of Sports Science, 4:84-89, 2016.

[46] R. Strange and L. Shamir. Prediction of football plays using pattern recognition. International Journal of Computer Science in Sport, 3(1):12-16, 2014.

[47] S. Svatora and L. Shamir. Improving eastern bluebird nest box performance using computer analysis of satellite images. Computational Ecology \& Software, $2(2), 2012$.

[48] L. Tsui. Effective strategies to increase diversity in stem fields: A review of the research literature. The Journal of Negro Education, pages 555-581, 2007.

[49] K. Ward. Research with undergraduates: a survey of best practices. Journal of Computing Sciences in Colleges, 21(1):169-176, 2005.

[50] L. Yaldo and L. Shamir. Computational estimation of football player wages. International Journal of Computer Science in Sport, In Press. 